\title{
A theoretical study on the heat transfer process in diesel engines
}

\author{
H. Fridriksson ${ }^{1}$, B. Sundén ${ }^{1} \&$ S. Hajireza ${ }^{2}$ \\ ${ }^{1}$ Department of Energy Sciences, Lund University, Sweden \\ ${ }^{2}$ Thermal and Combustion Technology, Sweden
}

\begin{abstract}
The current and future emissions regulations and demands on internal combustion engines have increased the need for improvement of the thermal design and engine efficiency. This paper reports an initial investigation concerning in-cylinder heat transfer. In addition, a literature review in this field is presented. It was found that no extensive application studies have been performed on full cylinder heat transfer by taking the effect of combustion and gas exchange into the account. The available literature is mainly focused on individual component studies and sub-model improvements.

Furthermore, a simple parameter study is performed in order to estimate the contribution of each parameter on the in-cylinder engine heat transfer. This is done by setting up an engine segment, using the commercial CFD tool AVL FIRE and the automatic mesh generator AVL Ese Diesel. Engine segment simulations are made for the period between IVC (intake valve closing) and EVO (exhaust valve opening). The parameter study revealed that most of the parameters selected do in-fact significantly affect the in-cylinder heat transfer. However, the effects on the indicated mean effective pressure, or indicated power output, are different.
\end{abstract}

Keywords: engine heat transfer, CFD, AVL FIRE, Parameter study.

\section{Introduction}

With todays strict requirements on internal combustion (IC) engine performance, with regards to emissions, it becomes more important to obtain optimized engine design, using computational fluid dynamics (CFDs) tools. The latest developments in IC engine design are leading towards smaller, more compact and efficient engines, which prove to be quite demanding on the combustion control and engine 
cooling. The major limitation to achieving higher efficiency of the modern IC engine is its thermodynamic cycle, i.e., the conversion of chemically released heat, through combustion, to mechanical work. With modern combustion schemes, the heat flux to the walls is highly transient, where the heat flux to a single wall can vary from zero to as much as $10 \mathrm{MW} / \mathrm{m}^{2}$ and back to zero again within 10 ms. Additionally, two locations on the wall separated by only $1 \mathrm{~cm}$ can receive peaks in heat flux differing in magnitude of up to $5 \mathrm{MW} / \mathrm{m}^{2}$. These loads are also subject to considerable cycle-to-cycle variations [1,2]. Predicting the spatial thermal distribution inside the engine cylinder during one engine cycle has proven to be a difficult task. Therefore, researchers often focus on one specific engine component, using somewhat simplified boundary conditions.

The combustion process of the diesel engine is a relatively well documented process, as described in [3-5], among others. Since the early days of combustion engine development, various experimental data have been used to foster the knowledge on the different phenomena occurring in the engine. This is, however, not always a feasible option, since the piston engine is not easily accessible for experimental measurements, and the probes and other apparatus used for experiments interfere with the natural flow field in the engine. Furthermore, in some experimental applications the material strength of the engine cylinder components has to be compromised for better visualization, e.g., quartz glass windows for optical measurements. This underlines the value of computational "experiments", e.g., in the form of CFD simulations for the combustion engine development. As CFD is a relatively new field within combustion engines, it is constantly being developed as the computational power is increased. The predecessor to modern computational simulations in engine heat transfer applications are the one dimensional steady state evaluations of the heat transfer coefficient. Borman and Nishiwaki [1] describe the transition of these heat transfer coefficient correlations from the empirical correlation presented by Nusselt in 1923 [6] and the more widely used empirical correlations presented by Eichelberg in 1939, towards the most commonly known correlations, based on the similarity law of steady turbulent heat transfer. The most widely known correlations of this form are the ones presented by Annand and Ma [7] and Woschni [8]. The historical use of the Woschni equation is exemplified by experimental situations, such as [9], and modified versions of the equation have been used in so-called "one-zone" models, as described by [10]. Today a range of one-dimensional simulation codes, often referred to as gas-exchange codes, make use of a modified version of the Woschni equation in the heat transfer assessment. Attempts have been made to contribute with new correlations for the heat transfer coefficient for 1-D codes, both for specific types of engines [11-13] and for specific parts of the engine [14]. Sanli et al. [15], presented a summary of the available correlations for SI-engines, as well as an evaluation of these, showing that they do in fact differ quite a bit in their predictions of heat flux and heat transfer coefficients.

In three-dimensional studies these gas-exchange codes are frequently used in order to provide starting values and/or boundary conditions for the simulations. This is especially true for the calculation of the temperature distribution in solid 
components of the engine, where the heat transfer coefficient is one of the boundary conditions, such as in [2]. Other studies, such as [16], use the onedimensional codes in order to obtain wall temperatures as boundary conditions, in order to simplify the computational domain. Along with more computational power, more and more researchers have included both the bulk gas and the solid regions in the computational domain, which means that the wall temperatures are resolved in the CFD simulation [17-23].

The development of CFD models for diesel engine application is an ongoing process. Reitz and Rutland [24] list a few of the models needed in order to successfully simulate a diesel engine cycle, as well as their development until 1995. Since then, there have been vast improvements, such as the formulation of temperature wall functions [25] and near wall treatment for turbulence in combination with conjugate heat transfer [26], to name a few.

In the work presented here, the effects of heat transfer from the variation of different geometrical and operational parameters are studied by using the CFD tools AVL FIRE and AVL ESE Diesel.

\section{Problem statement}

In order to determine the in-cylinder heat transfer for the different simulation cases presented in the next section, a segment of an engine cylinder was created using AVL ESE Diesel, and this is used throughout the simulation process. The engine geometrical parameters used in this work are specified in Table 1. The main computational grid consists of an average cell size ranging from 0.75 to 1.00 $\mathrm{mm}$. At the wall boundaries there are two layers, $0.20 \mathrm{~mm}$ in thickness, which are supposed to capture the phenomena occurring in the thermal boundary layer. The simulated segment only encloses a fuel spray from one orifice of the injection nozzle and the assumption of a cyclic symmetry is made. The number of angular subdivisions in this segment is 17 , i.e., there are 17 computational cells in the angular direction. These specifications lead to grid densities of 35.000 and 62.000 computational cells at TDC and BDC, respectively. The computational mesh of the combustion bowl at TDC is shown in Figure 1.

The governing equations for unsteady, compressible turbulent flow along with the energy equation and species transport were solved from IVC to EVO, by the

Table 1: Engine specifications.

\begin{tabular}{ll}
\hline Bore $[\mathrm{mm}]$ & 105 \\
Stroke $[\mathrm{mm}]$ & 120 \\
Conn.rod length $[\mathrm{mm}]$ & 200 \\
Piston pin offset [mm] & 0 \\
Compression ratio & $16: 1$ \\
No. of nozzle orifices & 7 \\
\hline
\end{tabular}




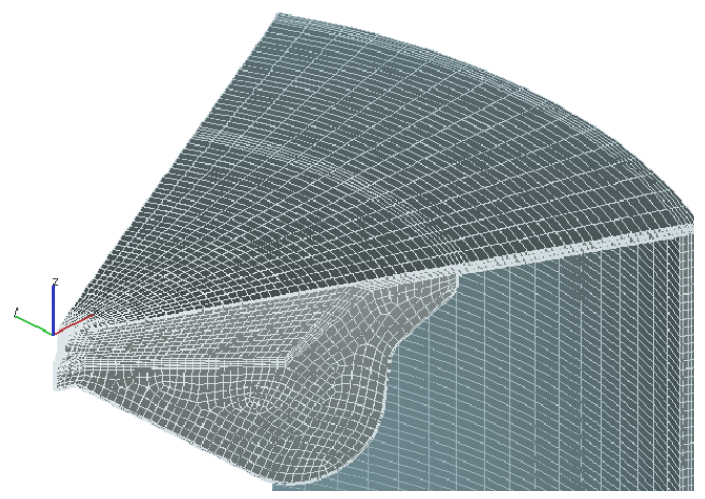

Figure 1: Mesh of the combustion bowl at TDC.

commercial CFD code AVL FIRE [27]. The turbulent flow field is modeled with the k-zeta-f model, using hybrid wall treatment and standard wall functions for the wall heat transfer. The combustion model used is the so-called ECFM-3Z version of the coherent flame model. Other physical phenomena accounted for in the simulation are evaporation and breakup, described by the Dukowitz and Wave models, respectively, while soot and NO formation are predicted by the Lund Flamelet model and the extended Zeldovich mechanism, respectively. All models used are described and referenced in the AVL FIRE v2009 user manual [27]. All initial and boundary conditions used in this work, and presented in the next section, were provided by a $1 \mathrm{D}$ gas exchange code simulation.

\section{Boundary conditions}

The duration time of the simulation is kept constant for all cases, i.e., the valve timings are not changed. The inlet valve is closed at 160 CAD before TDC (BTDC), while the exhaust valve opens at $130 \mathrm{CAD}$ after TCD (ATDC). The engine cylinder was initialized every simulation run with the pressure of 4.35 bar, temperature of $411 \mathrm{~K}$ and the swirl number of 1.5. The fuel used in the simulations was AVL's predefined diesel fuel and the EGR level at IVC was set to a mass fraction of $28 \%$. Out of these parameters, the swirl number and EGR level will be changed in the parameter sweep, presented in Table 2.

The total amount of fuel used in the whole cylinder is $98.32 \mathrm{mg}$, which means that the amount of fuel in the engine segment of the baseline case is roughly 14 $\mathrm{mg}$ (one seventh). The nozzle hole diameter, which is $0.169 \mathrm{~mm}$, determines the size of the biggest droplets inside the computational domain. The injection of fuel is started at the top most position of the piston (TDC) and as seen in Table 2 its duration varies from 30 to $34 \mathrm{CAD}$. The table even shows the variation in the spray angle, which varies from 140 to $160^{\circ}$, and engine speed, which varies from 2000 to 3000 RPM. Other parameters altered during the simulations are EGR level, 
Table 2: Values of the parameter sweep.

\begin{tabular}{lccc}
\hline Parameter & Lower value & Baseline & Higher value \\
\hline \hline Engine speed [RPM] & 2000 & 2500 & 3000 \\
EGR [-] & 0.25 & 0.28 & 0.35 \\
Injection dur. [CAD] & 30 & 32 & 34 \\
Swirl [-] & 1.4 & 1.5 & 1.8 \\
Spray angle [deg] & 140 & 160 & 180 \\
No. of inj. orifices [-] & 6 & 7 & 8 \\
\hline
\end{tabular}

swirl level and the number of injector holes, which calls for computational grids of different sizes since the computational domain only encloses one spray. The total number of simulation runs performed was therefore $1+12=13$ runs.

As for the thermal boundary conditions at the wall regions, all walls have been assigned constant temperatures. The piston wall and the cylinder head have both been assigned a temperature of $550 \mathrm{~K}$ and the cylinder liner has been assigned a temperature of $460 \mathrm{~K}$.

\section{Results}

In this section the result from the simulations will be presented in the form of heat flux to boundary walls and the corresponding heat transfer coefficients (HTC). In order to estimate the effect on the indicated engine output for each simulation run, the mean pressure trace will be used to evaluate the indicated mean effective pressure of the combustion stroke $\left(I M E P^{c o}\right)$. This value is not to be confused with the conventional engine IMEP, which is normally an estimation of the whole cycle, including the gas exchange part. Furthermore, to observe if the combustion itself will be affected in the simulation run, the rate of heat release (RoHR) is examined as a function of crank angle degree.

\subsection{Baseline case}

The heat flux values of the baseline case can be found in the first row of Table 3 as well as the solid lines of all the plots in Figure 2, where the rate of heat release, with the units $[J / C A D]$ is plotted as a function of crank angle degree. The rate of heat release curve presented here is typical for a diesel combustion, where there is a short peak in heat release shortly after injection ( $\sim 5 \mathrm{CAD})$, followed by a broader, longer peak. The shorter peak is representative for the premixed part of the combustion, while the larger, more dominant part, is representative for the diffusion flame. It is worth mentioning that the heat release curves presented here are scaled up to the full cylinder, i.e., the result for a 1/7 segment of the engine have 
182 Advanced Computational Methods and Experiments in Heat Transfer XI

Table 3: Heat transfer and indicated mean pressure results for all cases.

\begin{tabular}{l|rrr|rrr|r}
\hline & \multicolumn{1}{|c}{ Heat flux [W] } & HTC [W/m ${ }^{2}$ K] & IMEP $^{c o}$ \\
\hline & Head & Liner & Piston & Head & Liner & Piston & \\
\hline \hline Baseline & 862 & 418 & 1098 & 1432 & 1587 & 1523 & 15.79 \\
\hline \hline \multicolumn{7}{c}{ Engine speed [RPM] } \\
\hline 2000 & 707 & 355 & 892 & 1225 & 1331 & 1297 & 15.58 \\
3000 & 1027 & 495 & 1286 & 1638 & 1835 & 1739 & 15.92 \\
\hline \multicolumn{7}{c}{ EGR mass fraction [-] } \\
\hline $25 \%$ & 872 & 431 & 1095 & 1434 & 1586 & 1521 & 15.79 \\
$35 \%$ & 856 & 430 & 1084 & 1432 & 1586 & 1523 & 15.71 \\
\hline \multicolumn{7}{c}{ Swirl number [-] } \\
\hline 1.4 & 872 & 442 & 1083 & 1420 & 1565 & 1506 & 15.74 \\
1.8 & 842 & 393 & 1108 & 1489 & 1662 & 1567 & 15.77 \\
\hline \multicolumn{7}{c}{ Spray angle [deg] } \\
\hline 140 & 746 & 344 & 1244 & 1456 & 1594 & 1561 & 16.04 \\
180 & 562 & 238 & 1125 & 1447 & 1574 & 1683 & 9.24 \\
\hline \multicolumn{7}{c}{ Injection duration [CAD] } \\
\hline 30 & 922 & 411 & 1133 & 1443 & 1596 & 1536 & 16.04 \\
34 & 815 & 438 & 1052 & 1429 & 1577 & 1508 & 14.48 \\
\hline \multicolumn{7}{c}{ Number of injection holes [-] } \\
\hline 6 & 1183 & 545 & 1348 & 1461 & 1600 & 1546 & 15.99 \\
8 & 666 & 341 & 906 & 1438 & 1576 & 1506 & 15.39 \\
\hline
\end{tabular}

been multiplied by 7 in order to obtain the total rate of heat release for the cylinder. As mentioned above, Table 3 includes values for the IMEP of the combustion, which is around 15.79 bar for the baseline case. The values for the heat flux and the heat transfer coefficient for each wall, presented in the table, are the integrated values for the entire wall surface and therefore have the unit $[W]$. The results show that in this case the total heat transfer during the combustion phase is highest at the piston surface.

\subsection{Engine speed}

From the heat release curve, at the top left corner of Figure 2, it can be seen that the effects of engine speed are most clearly visible in the "premixed" part of the combustion process, during the first five crank angle degrees. The effects of engine 

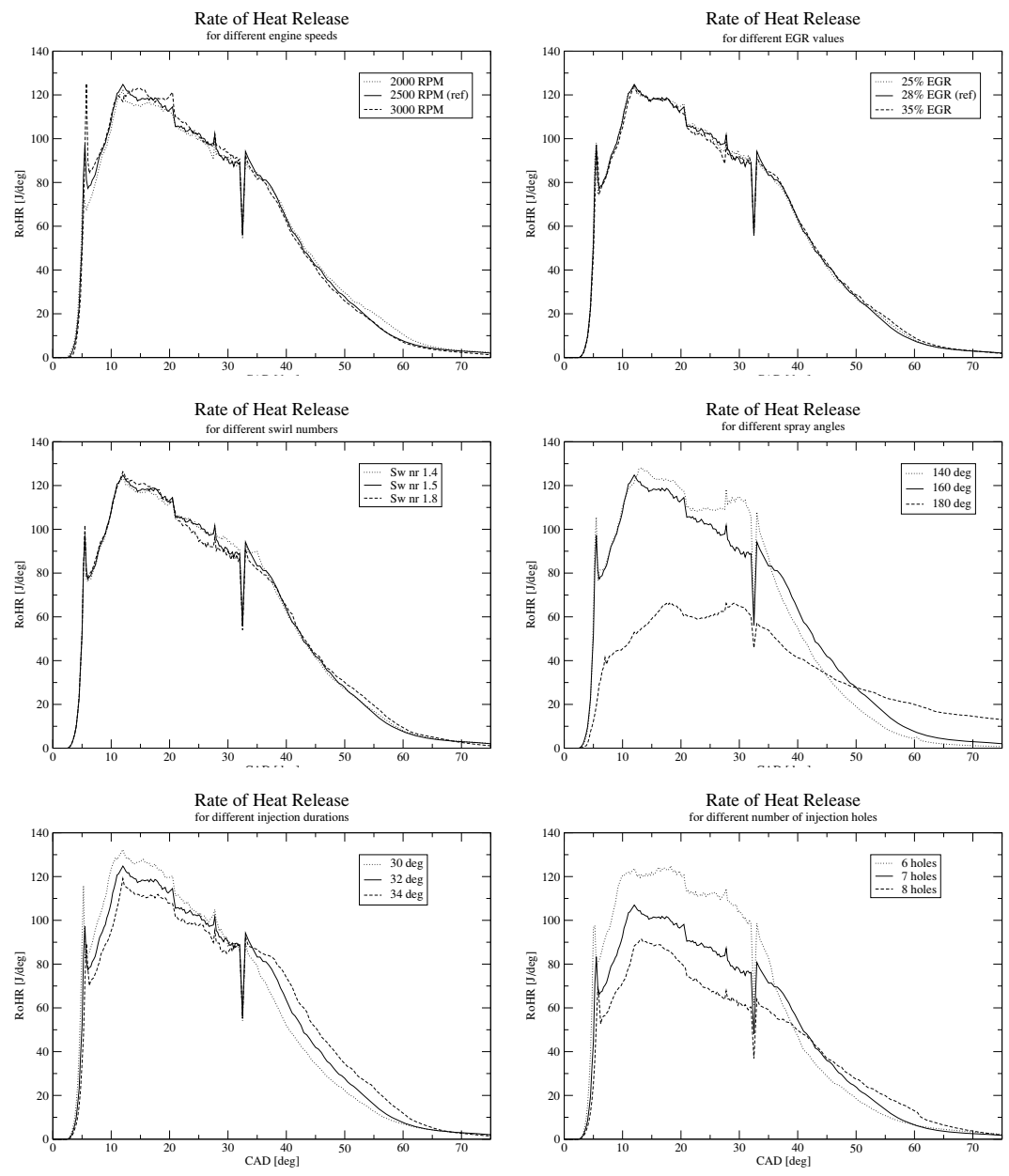

Figure 2: Rate of heat release for all the simulation runs.

speed, however, seem to be less on the diffusion flame, which occurs later in the expansion stroke of the engine. When examining the values in Table 3, it can be found that without considerable change in the output effect $\left(\operatorname{IMEP}^{c o}\right)$, the heat transfer characteristic shows a considerable change with variable engine speeds. It is evident that with doubled engine speed, the heat transfer rate to the walls is roughly doubled. This is somewhat expected, since the gas velocity inside the engine cylinder scales with piston speed and therefore, the heat transfer also scales almost linearly with the piston speed. 


\subsection{EGR}

The effects of EGR level variation on the rate of heat release are shown at the top right corner of Figure 2. Changing the EGR mass fraction from 0.25 to 0.35 does not seem to effect the heat release rate. This might indicate that there is enough amount of oxidants in the system to completely combust the fuel in the cylinder, even though combustion products are recirculated into the combustion event. The values from the table show that the effects on wall heat transfer are minimal, but the trend in the effect output show a small decrease in IMEP ${ }^{c o}$ with a higher EGR mass fraction. Normally EGR is used in combustion engines in order to lower the combustion temperature for the purpose of emission control. This is usually followed by a penalty in the output effect, shown here by the decreasing trend of the IMEP ${ }^{c o}$ variable.

\subsection{Swirl}

The heat transfer results for swirl in Table 3 show no significant change in the wall heat flux for the piston and head surfaces, but a slight decrease $(\sim 11 \%)$ in liner heat flux was discovered with an elevated swirl number from 1.4 to 1.8. The values for the integrated heat transfer coefficient are a bit more sensitive to the change in swirl level. The values for the IMEP ${ }^{c o}$ show a minimal increase with the higher swirl number. The effects on the heat release rate, shown in the middle left part of Figure 2, are almost non-existent. The swirl level normally enhances the mixing of fuel and air in the combustion bowl and the almost non-existent change in effect and heat transfer characteristics indicate that this swirl level does not severely effect the fuel-air mixing inside the current combustion bowl shape.

\subsection{Spray angle}

The effects on the heat release rate from variable spray angle are shown in the middle left part of Figure 2. The heat release rate seems to be extremely sensitive to the angle with which the fuel is injected at. Each combustion bowl shape has its optimal injection angle, for the best possible fuel-air mixing process. For this particular bowl shape, the $140^{\circ}$ injection angle seems to provide the best fuelair mixing, as well as the highest IMEP ${ }^{c o}$. This, however, comes with the price of higher heat fluxes to all wall surfaces. The extremely poor combustion for the $180^{\circ}$ angle can be explained by the fact that the fuel is injected along the cylinder head and most likely straight into the squish area. This will lead to poor fuel-air mixing and poor combustion, leading to low peak temperatures and low mechanical work output.

\subsection{Injection duration}

Changing the duration time of the fuel injection, keeping the total fuel mass constant, clearly effects both the heat release rate and the wall heat transfer, as shown 
in the bottom left corner of Figure 2 and Table 3. Furthermore, increasing the duration of 4 CAD lowers the IMEP ${ }^{c o}$ from $\sim 16$ bar to $\sim 14.5$ bar. It is clear that with a shorter injection duration, more fuel is injected at each crank angle degree and assuming that there is enough oxygen for complete combustion, the shorter injection duration should increase the heat release rate during the injection. In this case it seems to be so.

\subsection{Number of injection holes}

With the number of injection holes changed from six to eight, seven being the reference case, there seems to be a significant impact on the heat release rate and the wall heat transfer, without significant changes in the combustion IMEP. This is the only case in this $12+1$ simulation runs which has required the generation of new meshes for each parameter, i.e., the size of the three engine segment meshes here is not the same $(1 / 6,1 / 7$ and $1 / 8)$. This means that the computational volume has changed, however, the total amount of fuel injected in the segment was adjusted accordingly. Since the volume has changed, the segment including the smaller volume might encounter stronger interactions with the adjacent spray, i.e., the cyclic symmetry assumption might be somewhat questionable for a too small volume.

\section{Discussion}

The literature study included in the introduction shows that the knowledge on the heat transfer processes in the combustion engine is a vital subject for the optimized operation of the engine. Today there are few investigations that have focused on the cylinder as a whole when it comes to heat transfer applications, whereas most researchers have chosen, for various reasons, to focus on individual engine components or improvements on individual models. The combination of those should, however, be used in an application study in order to quantify the effect of heat transfer at various load points and configurations.

From the engine segment simulation parameter study, it can be assumed that for the given combustion bowl the injection properties, i.e., spray angle and injection duration etc., are critical when it comes to wall heat transfer. This is mostly due to the fact that these parameters determine the quality of the combustion, and therefore the peak temperature achieved in the combustion phase. Other parameters that significantly effect wall heat transfer for the given combustion bowl shape showed to be engine speed and number of injection nozzles. It is clear that for any combustion bowl shape, the heat transfer coefficient and, therefore, wall heat fluxes will scale with the bulk gas velocity, which scales linearly with the piston speed. However, the observed effects from the number of injection nozzles on the wall heat transfer are somewhat unexpected and need further investigation.

The fact that the EGR mass fraction did not effect the wall heat fluxes more than observed, was not really expected. This might, however, be explained by the fact that the load point selected in this case, i.e., amount of fuel used etc., cancels out 
the expected cooling effects of an elevated EGR mass fraction. In this moderate, as it seems, load point, the fuel is fully consumed even though more EGR is used, indicating sufficient oxygen levels in the mixture at all times.

No significant changes in wall heat transfer were observed for the variation of swirl levels. The values chosen were obviously not far enough apart to effect the combustion and heat transfer processes, since the load point was not a full load one. This should in fact be examined with a full load case for more detailed evaluation, since at a full load point the fuel-air mixing should be more sensitive to variation in swirl levels.

\section{Conclusions}

Further knowledge on the temperature distribution inside an engine cylinder as well as the heat transfer process is critical in order to produce engines with higher specific power output, as well as lower emissions. In theory, the theoretical efficiency of the diesel thermodynamic cycle is proportional to the ratio of the peak temperature and the ambient inlet temperature in the system. This poses requirements on the material side which have no solutions, so in order to raise the efficiency of the engine, a detailed knowledge of the thermodynamic behavior of the system is required. This work is a first step on the way towards deeper understanding of this phenomenon, and the parameter study included in this paper highlights briefly how some parameters can affect the in-cylinder heat transfer. This study should be extended to include more parameters and evaluation of the individual models used to obtain the current results.

\section{Acknowledgement}

The Swedish Energy Agency financially supports this project.

\section{References}

[1] Borman, G. \& Nishiwaki, K., Internal-combustion engine heat transfer. Progress in energy and combustion science, 13(1), pp. 1-46, 1987.

[2] Liu, Z., Jiang, Y., Dong, Z., Pi, B. \& Liu, Y., 3-D Numerical Simulation of Transient Heat Transfer among Multi-Component Coupling System in Internal Combustion Chamber. SAE International, 2008. 2008-01-1818.

[3] Heywood, J., Internal Combustion Engine Fundamentals. McGraw-Hill: New York, NY, 1988.

[4] Kamimoto, T. \& Kobayashi, H., Combustion processes in diesel engines. Progress in Energy and Combustion Science, 17(2), pp. 163-189, 1991.

[5] Johansson, B., Förbränningsmotorer. Lund University: Lund, Sweden, 2006. (in Swedish).

[6] Nusselt, W., Der Wärmeübergang in der Verbrennungskraftmaschine. Z Ver Dt Ing, 67, p. 692, 1923. 
[7] Annand, W. \& Ma, T., Instantaneous heat transfer rates to the cylinder head surface of a small compression-ignition engine. Proceedings of the Institution of Mechanical Engineers, 185, pp. 976-987, 1970.

[8] Woschni, G., Universally applicable equation for the instantaneous heat transfer coefficient in the internal combustion engine. SAE International, 1967. 670931.

[9] Torregrosa, A., Olmeda, P., Degraeuwe, B. \& Reyes, M., A concise wall temperature model for DI diesel engines. Applied Thermal Engineering, 26(11-12), pp. 1320-1327, 2006.

[10] Descieux, D. \& Feidt, M., One zone thermodynamic model simulation of an ignition compression engine. Applied Thermal Engineering, 27(8-9), pp. 1457-1466, 2007.

[11] Beary, A., Study on Heat Transfer Correlations in IC Engines. SAE International, 2008. 2008-01-1816.

[12] Galindo, J., Luján, J., Serrano, J., Dolz, V. \& Guilain, S., Description of a heat transfer model suitable to calculate transient processes of turbocharged diesel engines with one-dimensional gas-dynamic codes. Applied Thermal Engineering, 26(1), pp. 66-76, 2006.

[13] Soyhan, H., Yasar, H., Walmsley, H., Head, B., Kalghatgi, G. \& Sorusbay, C., Evaluation of heat transfer correlations for HCCI engine modeling. Applied Thermal Engineering, 29(2-3), pp. 541-549, 2009.

[14] Depcik, C. \& Assanis, D., A universal heat transfer correlation for intake and exhaust flows in an spark-ignition internal combustion engine. $S A E$ International, 111(3), pp. 734-740, 2002.

[15] Sanli, A., Sayin, C., Gumus, M., Kilicaslan, I. \& Canakci, M., Numerical Evaluation by Models of Load and Spark Timing Effects on the In-Cylinder Heat Transfer of a SI Engine. Numerical Heat Transfer, Part A: Applications, 56(5), pp. 444-458, 2009.

[16] Hajireza, S., Regner, G., Christie, A., Egert, M. \& Mittermaier, H., Application of CFD Modeling in Combustion Bowl Assessment of Diesel Engines using DoE Methodology. SAE International, 2006. 2006-01-3330.

[17] Liu, Y. \& Reitz, R., Modeling of heat conduction within chamber walls for multidimensional internal combustion engine simulations. International Journal of Heat and Mass Transfer, 41(6-7), pp. 859-869, 1998.

[18] Kojima, T. \& Nishiwaki, K., Numerical analysis of heat transfer in heat insulated diesel engines. JSAE Review, 15(2), pp. 133-140, 1994.

[19] Kajiwara, H., Fujioka, Y., Suzuki, T. \& Negishi, H., An Analytical Approach for Prediction of Piston Temperature Distribution in Diesel Engines. Proceedings JSAE Annual Congress, pp. 9-12, 2002.

[20] Urip, E., Liew, K., Yang, S. \& Arici, O., Numerical Investigation of Heat Conduction with Unsteady Thermal Boundary Conditions for Internal Combustion Engine Application. Proceedings of IMECE04 2004 ASME International Mechanical Engineering Congress and Exposition, IMECE2004$59860,2004$. 
188 Advanced Computational Methods and Experiments in Heat Transfer XI

[21] Urip, E., Liew, K. \& Yang, S., Modeling IC Engine Conjugate Heat Transfer Using the KIVA Code. Numerical Heat Transfer Part A: Applications, 52(1), pp. 1-23, 2007.

[22] Noori, A. \& Rashidi, M., Computational Fluid Dynamics Study of Heat Transfer in a Spark-Ignition Engine Combustion Chamber. Journal of Heat Transfer, 129, p. 609, 2007.

[23] Mohammadi, A., Yaghoubi, M. \& Rashidi, M., Analysis of local convective heat transfer in a spark ignition engine. International Communications in Heat and Mass Transfer, 35(2), pp. 215-224, 2008.

[24] Reitz, R. \& Rutland, C., Development and Testing of Diesel Engine CFD Models. Progress Energy Combustion Science, 21, pp. 173-196, 1995.

[25] Han, Z. \& Reitz, R., A temperature wall function formulation for variabledensity turbulent flows with application to engine convective heat transfer modeling. International Journal of Heat and Mass Transfer, 40(3), pp. 613 $625,1997$.

[26] Nuutinen, M., Kaario, O. \& Larmi, M., Conjugate Heat Transfer in CI Engine CFD Simulations. SAE International, 2008. 2008-01-0973.

[27] Avl fire v2009 user manual., 2009. 